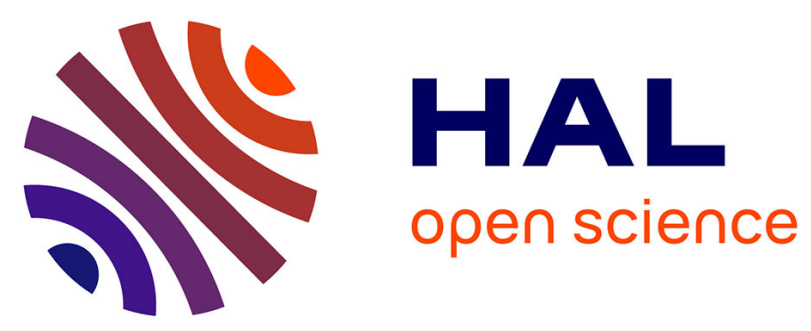

\title{
Exposure to pesticides and risk of childhood cancer:a meta-analysis of recent epidemiological studies
}

\author{
Florence Vinson, Maysaloun Merhi, Isabelle Baldi, Helene H. Raynal, \\ Laurence Gamet-Payrastre
}

\section{To cite this version:}

Florence Vinson, Maysaloun Merhi, Isabelle Baldi, Helene H. Raynal, Laurence Gamet-Payrastre. Exposure to pesticides and risk of childhood cancer:a meta-analysis of recent epidemiological studies. Occupational and Environmental Medicine, 2011, 68, pp.694-702. 10.1136/oemed-2011-100082 . hal02650883

\section{HAL Id: hal-02650883 \\ https://hal.inrae.fr/hal-02650883}

Submitted on 29 May 2020

HAL is a multi-disciplinary open access archive for the deposit and dissemination of scientific research documents, whether they are published or not. The documents may come from teaching and research institutions in France or abroad, or from public or private research centers.
L'archive ouverte pluridisciplinaire HAL, est destinée au dépôt et à la diffusion de documents scientifiques de niveau recherche, publiés ou non, émanant des établissements d'enseignement et de recherche français ou étrangers, des laboratoires publics ou privés. 


\title{
Exposure to pesticides and risk of childhood cancer: a meta-analysis of recent epidemiological studies
}

\author{
Florence Vinson, ${ }^{1}$ Maysaloun Merhi, ${ }^{1}$ Isabelle Baldi, ${ }^{2}$ Hélène Raynal, ${ }^{3}$ \\ Laurence Gamet-Payrastre ${ }^{1}$
}

- Additional materials are published online only. To view these files please visit the journal online (http://oem.bmj. com).

${ }^{1}$ INRA, TOXALIM, Toulouse, France

${ }^{2}$ LSTE, ISPED, University of Bordeaux, Bordeaux, France ${ }^{3}$ INRA, BIA, Toulouse, France

\section{Correspondence to}

Laurence Gamet-Payrastre, INRA, UMR1089 Xénobiotiques, 180 Chemin de Tournefeuille, BP93173, F-31027 Toulouse Cedex 3, France; Laurence. Payrastre@toulouse.inra.fr

Accepted 15 April 2011 Published Online First 23 May 2011

\section{ABSTRACT}

Objectives The authors performed a meta-analysis of case-control and cohort studies to clarify the possible relationship between exposure to pesticides and childhood cancers.

Methods Two cohort and 38 case-control studies were selected for the first meta-analysis. After evaluating homogeneity among studies using the Cochran 0 test, the authors calculated a pooled meta-OR stratified on each cancer site. The authors then constructed a list of variables believed to play an important role in explaining the relation between parental exposure to pesticide and childhood cancer, and performed a series of meta-analyses. The authors also performed a distinct meta-analysis for three cohort studies with RR data.

Results Meta-analysis of the three cohort studies did not show any positive links between parental pesticide exposure and childhood cancer incidence. However, the meta-analysis of the 40 studies with OR values showed that the risk of lymphoma and leukaemia increased significantly in exposed children when their mother was exposed during the prenatal period $(\mathrm{OR}=1.53 ; 95 \% \mathrm{Cl}$ 1.22 to 1.91 and $\mathrm{OR}=1.48 ; 95 \% \mathrm{Cl} 1.26$ to 1.75$)$. The risk of brain cancer was correlated with paternal exposure either before or after birth $(\mathrm{OR}=1.49 ; 95 \% \mathrm{Cl}$ 1.23 to 1.79 and $\mathrm{OR}=1.66$; $95 \% \mathrm{Cl} 1.11$ to 2.49 ). The $\mathrm{OR}$ of leukaemia and lymphoma was higher when the mother was exposed to pesticides (through household use or professional exposure). Conversely, the incidence of brain cancer was influenced by the father's exposure (occupational activity or use of household or garden pesticides).

Conclusion Despite some limitations in this study, the incidence of childhood cancer does appear to be associated with parental exposure during the prenatal period.

\section{INTRODUCTION}

Childhood cancer is the second leading cause of death among children aged 5-14 years after accidental causes in Europe and the USA (NCI, http:// www.cancer.gov). ${ }^{12}$ Among the 12 major types of childhood cancer, the leukaemia group has the highest incidence ( $40 \%$ of all cancers); cancers of the brain, lymphomas and cancers of central nervous system account for more than $25 \%$ of new cases; neuroblastoma, Wilms' tumour and sarcoma are less common. ${ }^{3-5}$ In the USA and Europe, there is concern that overall rates of childhood cancer have been increasing since $1970 .^{6}$ The risk factors for childhood cancer are largely unknown. A few conditions such as Down's syndrome, other specific

\section{What this paper adds}

The aim of our study was to perform a meta-analysis of case-control and cohort studies to clarify the possible relationship between exposure to pesticides and childhood cancer sites. Our results from $\mathrm{OR}$ values show that the risk of brain cancer, leukaemia and lymphoma in childhood is significantly associated with parental exposure and that the prenatal period is a critical window of exposure to these compounds. All the results presented in our manuscript as well as those published elsewhere add to the evidence leading us to recommend minimising parental occupational exposure to pesticides

chromosomal and genetic abnormalities, and exposure to ionising radiation are known risk factors, but they explain only a small percentage of cases. 78 Early-life exposure to environmental contaminants is suspected to be responsible for initial anomalies occurring in utero and leading to cancer. ${ }^{9} 10$

Pesticides are among the suspected environmental factors, as they may promote cellular and molecular events, that is, chromosomal aberrations, oxidative stress, cell signalling disturbances or mutations, that could be linked to increased cancer risk. $^{11-13}$ In a review of epidemiological studies in 1997, Daniels et al ${ }^{14}$ showed that frequent occupational exposure to pesticides or use of pesticides in the home was associated with childhood leukaemia, brain cancer and increased risk of Wilms' tumour, Ewing's sarcoma and germ-cell tumours. Living on a farm, a proxy for pesticide exposure, was also associated with increased risk of a number of childhood cancers in studies investigating associations between pesticide exposure and childhood cancers. ${ }^{14}$ Another review of epidemiological studies and childhood cancers ${ }^{15}$ revealed conflicting evidence across studies with regard to cancer types as well as to risk factors, and no clear data exist regarding the most critical exposure period for the occurrence of cancer.

The aim of our study was to perform a metaanalysis of case-control and cohort studies in a comprehensive overview of all available knowledge and to clarify the possible relationships between exposure to pesticides and childhood cancers. We focused on the site of the cancer, the period and the duration of exposure among studies that have calculated their evaluation of risk with 
OR. The subjects considered were reported to have been potentially exposed to pesticides after birth, during pregnancy, before conception or 'ever.' The type of exposure covered occupational exposure (farmers or chemical-industry employees), home and garden use as well as exposure due to the proximity of the home to an agricultural area. We have also separately performed a meta-analysis with three cohorts that have evaluated the $R R$.

\section{MATERIALS AND METHODS Study identification}

We started our study with a review of epidemiological literature on PubMed (http://www.ncbi.nlm.nih.gov). An electronic search using the terms 'pesticides' AND 'childhood cancer' was initially undertaken to find a list of relevant articles. This was supplemented by various combinations of the following keywords: fungicide, herbicide, insecticide, cancer risk, childhood tumour, leukaemia, lymphoma, brain tumour, neonatal exposure, residential exposure, occupational exposure, household pesticides, germ cell tumour and childhood sarcoma haematopoietic cancers, using the AND operating term to complete the search. As a result, we compiled a set of epidemiological studies (published between 1985 and 2008) on the impact of childhood exposure on the risk of developing cancer at any site.

\section{Selection of studies}

Studies were excluded if:

- they were not published in English;

- they did not provide sufficient data (for example information was missing on the number of cases and controls, the period of exposure, the person exposed);

- an insufficient number of cases or controls were included (fewer than five) because statistical analyses are less robust;

- they included data resulting from accidental exposure. Studies were included in the analysis when they complied with the following inclusion criteria:

- case-control or cohort studies with calculation of ORs and RRs

- were published in peer reviewed journals;

- were published between 1985 and 2008;

- included any site of childhood cancer;

- referred to the period of exposure (preconception and/or fetal and/or postnatal and 'ever' exposure, the latter corresponding to an unspecified period).

- In the case of prenatal exposure, we also included data concerning exposure before conception. The OR was determined after gathering all data related to the exposure of the mother, father and both parents. When considering exposure before pregnancy, the authors included the two parents, and when considering exposure during pregnancy, they included only the mothers.

- In the case of postnatal exposure, parents had either agricultural or non-agricultural occupations or used pesticides at home or in the garden. In some studies, exposure was due to the use of professional pest control services (indoor or outdoor).

- Data concerning exposure classified as 'ever' (corresponding to an unspecified period of exposure by authors) were kept aside and analysed separately.

- Parents had either agricultural (farmers, farm workers) or non-agricultural occupations (chemical industry, pest controller).

- In some studies, exposure concerned the use of professional pest-control services (indoor or outdoor).
All identified studies were reviewed by two reviewers, and only studies that met the inclusion criteria were retained.

Data extraction (tables $\mathbf{1 a}$ and $\mathbf{b}$ (online) in additional data) ${ }^{\mathbf{1 6 - 5 9}}$ The following general and methodological information was abstracted from each paper: name of authors, country and year of publication, type of epidemiological study (cohort or casecontrol), age and sex of children, site of cancer observed, person exposed (mother, father, both parents or child), characteristics of the type of exposure (eg, occupational/non-occupational), period (eg, pre- or postnatal, preconception, both), duration (eg, lifelong or occasional) and frequency, type and value of the calculated risks (OR or RR) with their $95 \%$ CIs, statistical method used in each study, data concerning the identity of pesticides and the number of cases and controls exposed or not, when these data were available. Articles that met the criteria of exclusion and inclusion were tabulated in an Excel spreadsheet for use in the meta-analysis. Table 1 (online) lists the most relevant and helpful information for the reader: type of cancer, age of the children, period of diagnosis, type, period and frequency of exposure, pesticide used, and estimated ORs with their 95\% CIs. The main childhood cancers examined were cancers of the central nervous system (including astrocytoma, medulloblastoma, ependymoma and glioma), germ-cell tumours, leukaemia (plus different subtypes: lymphoblastic acute leukaemia (LAL), lymphoblastic non-acute leukaemia, acute leukaemia (AL)), nonHodgkin's lymphoma, kidney tumours, Hodgkin's disease, softtissue sarcoma, Ewing's sarcoma and neuroblastoma.

\section{Data analysis}

\section{Statistical pooling}

Because the method used in our meta-analysis cannot mix OR and $R R$ values in the determination of the pooled OR, we performed two separate meta-analysis; the first using the 304 ORs listed in table $1 \mathrm{a}$ (online) (additional data) ${ }^{16-56}$ and another using the RRs values of three studies ${ }^{57-59}$ listed at the end of table 1a (online).

The calculation of pooled ORs and pooled RRs was performed using the same method described below.

Each manuscript generally assessed several sources of exposure so that several ORs or RR were provided in the same article. When the ORs or RRs were calculated for different subpopulations of the same sample, we considered them separately, and all were taken into account in the meta-analyses.

To calculate the pooled-estimates (meta-OR or meta-RR) and their CI, we first used a fixed-effect model (Mantel-Haenszel method $^{60}$ ). As the homogeneity hypothesis did not appear to be suitable, we used a random-effect model. The estimation was made according to the DerSimonian and Laird method. For each model, a test for overall effect was performed. The $p$ values showed a significant effect of exposure on cancer risk in both cases.

In the Mantel-Haenszel fixed-effect model the estimated pooled OR or RR $\hat{\theta}$ equals $\hat{\theta}=\sum \theta_{\mathrm{i}} \omega_{\mathrm{i}} / \sum \omega_{\mathrm{i}}$ where $\theta_{\mathrm{i}}$ is the OR for the ith study and its weight $\omega_{i}=b_{i} c_{i} / N_{i} ; a_{i}$ and $b_{i}$ are the number of persons exposed to pesticides and who had or did not develop a cancer respectively; and $c_{i}$ and $d_{i}$ are people who were not exposed (or controls), who had or did not have a cancer respectively. $N_{i}$ is the total number of persons included in each study.

Because of the heterogeneity of our studies, the random-effect model was more appropriate. Using this model, the estimate of the pooled effect and its CI incorporate additional variability due to between-study variance $\left(\tau^{2}\right)$. As detailed by DerSimonian and 
Laird, ${ }^{61}$ an ${ }_{2}$ estimator of $\tau^{2}$ is defined as $\hat{\tau}^{2}=\max$, where $\mathrm{Q}=\sum \mathrm{w}_{\mathrm{i}} \hat{\theta}_{\mathrm{i}}^{2}-\left(\mathrm{w}_{\mathrm{i}} \hat{\theta}_{\mathrm{i}}\right)^{2} / \sum \mathrm{w}_{\mathrm{i}}$, and $\mathrm{K}$ represents the total number of studies.

In the DerSimonian and Laird method, ${ }^{61}$ the estimated pooled OR $\hat{\theta}$ equals $\hat{\theta}=\sum \theta_{\mathrm{i}} \omega_{\mathrm{i}}^{*} / \sum \omega_{\mathrm{i}}^{*}$ where $\theta_{\mathrm{i}}$ is the OR for ith study and its weight $\mathrm{w}_{\mathrm{i}}^{*}=\left(\operatorname{vâr}\left(\hat{\theta}_{\mathrm{i}}\right)+\hat{\tau}^{2}\right)^{-1}$. Evaluation of homogeneity was performed using the same method for the calculation of pooled $\mathrm{OR}$ and $\mathrm{RR}$.

The next step was to determine the degree of homogeneity among the studies. The test for this hypothesis is based on the Cochran $\mathrm{Q}$ test with a degree of freedom equal to the number of studies minus 1 and tests the null hypothesis that the withinstudy estimates of ORs are homogenous across all the studies. ${ }^{62}$ The $p$ value (we considered $p<0.05$ to be statistically significant) indicates the presence or not of heterogeneity among the studies. When the hypothesis of homogeneity among studies appeared to be invalid, we worked with a random-effect model ${ }^{61}$ that incorporates the estimation of the pooled effect size, and its $\mathrm{CI}$ incorporates the additional variability due to between-study variance, ${ }^{62}$ although there are some limitations to the use of a random-effect model. ${ }^{63}$

\section{Analysis}

We calculated a meta-OR or a meta-RR for types of cancer. It is worth noting that this method accounts for the weight of each study. ${ }^{60} 62$ To investigate possible sources of heterogeneity, we stratified the studies into each site or subtype of cancer as cited by the authors, non-Hodgkin's and Hodgkin's lymphoma, leukaemia (acute lymphoblastic and myeloid leukaemia AML, ALL, LANL), brain cancer, germ-cell tumours, kidney cancer, Ewing's sarcoma and neuroblastoma, and performed a metaanalysis for each. We defined a list of parameters including the exposure setting (occupational/non-occupational, eg, living in an agricultural area, use of pesticides in the home or garden) and the period of exposure (eg, pre- or postnatal or 'ever'), and performed a meta-analysis for each parameter concerned.

\section{Publication bias}

We explored the effect of the study size by plotting the logarithm of the estimator of OR versus its SE. Publication bias is characterised by asymmetry of the funnel plot determined by the Egger test. ${ }^{64}$ We used the Duval and Tweedie ${ }^{65}$ non-parametric 'trim and fill' method of accounting for publication bias in meta-analyses. The method, a rank-based data-augmentation technique, formalises the use of funnel plots, estimates the number and outcomes of missing studies, and adjusts the metaanalysis to incorporate the theoretical missing studies.

\section{Software}

All analyses were conducted using Stata/IC 10 (Stata Corporation, PC).

\section{RESULTS}

In our PubMed search, we identified 50 articles related to childhood cancer and pesticides. According to our selection criteria (described in Materials and methods), 40 epidemiological studies (two cohorts and 38 case-control studies with OR values $^{16-56}$ ) were eligible based on inclusion and exclusion criteria, and were selected for the meta-analysis. ${ }^{5} 6$ In these studies, 62 risk estimates were identified from both cohort and case-control studies (table 1 (online)). Among all the values included, 96 showed a significant positive association between exposure to pesticides and childhood cancers. Briefly, 36 OR concerned the risk of Hodgkin's and non-Hodgkin's lymphoma, 110 the risk of leukaemia (acute, lymphoid and myeloid), 95 the risk of brain tumour, 18 the risk of germ-cell tumour, and six, nine and four the risk of renal tumour, Ewing's sarcoma and neuroblastoma respectively. Except data from Cordier et al, ${ }^{25}$ Valery et $a l^{26}$ and Olshan et $a l^{42}$ most studies provided information on who was exposed (both parents, father, mother or child), the period and the length of exposure. Also, in most studies, the authors provided precise information on the type of exposure (occupational or the use of pesticides in the home or garden, environmental exposure due to living close to an agricultural area, or the intervention of a pest controller outside or inside the home). Fourteen studies ${ }^{23} 27313234-37464952-5466$ mentioned the class of pesticides used. Briefly, eight concerned the use of an insecticide, herbicide or fungicide by the parents at home or in the garden; three concerned the professional use of an insecticide, herbicide or fungicide, and two concerned herbicide spraying by a pest controller. Two studies were performed in a population living near an intensive agriculture area where insecticides, herbicides and fungicides were used. Three studies corresponded to cohort studies with RR values. ${ }^{57-59}$

\section{EXPOSURE TO PESTICIDES AND INCIDENCE OF EACH TYPE OF CHILDHOOD CANCER}

The separate meta-analysis of the three cohort studies with RR data did not show any positive link between pesticide exposure of parents and leukaemia (seven values, fixed model, $\mathrm{OR}=0.95$; $95 \%$ CI 0.81 to 1.11 ), lymphoma (four values, random model $\mathrm{OR}=1.08 ; 95 \% \mathrm{CI} 0.71$ to 1.65 ) and brain cancer (eight values, random model $\mathrm{OR}=1.035 ; 95 \%$ CI 0.80 to 1.34 ) incidences.

However, different results were obtained in the meta-analysis of the 40 studies with OR values. Bias was observed only in data on brain tumours as shown by the asymmetry of the funnel plot in figure 1. To correct for this publication bias, we applied the 'trim and fill' method. ${ }^{65}$ To make the funnel plot symmetrical, the method added 12 studies presumed to be missing. The corresponding OR decreased from $22 \%$ to $17 \%$ after application of the 'trim and fill' method but was still significant ( $O R=1.17 ; 95 \%$ CI 1.09 to 1.26 ). The hypothesis of a positive correlation between exposure to pesticides and the incidence of childhood brain cancer was still relevant. To explain the remaining heterogeneity after exploration of the publication bias, we performed a stratified analysis by type or subtype of cancer. For most cancers, the results demonstrated differences in effect among the OR (data not shown). A random model was used for analysis, except for germ-cell tumours and renal tumours for which a fixed model was used. For nonHodgkin's lymphoma and Hodgkin's lymphoma, 36 OR were analysed, 110 OR for leukaemia (acute, lymphoid or myeloid), 95 OR for brain cancer, 18 OR for germ cell tumours, eight OR for renal cancer, nine OR for Ewing's sarcoma and four OR for neuroblastoma. Tests using Cochran $\mathrm{Q}$ statistics demonstrated a high heterogeneity, and the hypothesis of an identical effect for all studies was rejected. A meta-analysis revealed a significant increase in the incidence of lymphoma $(\mathrm{OR}=1.37 ; 95 \% \mathrm{CI}$ 1.22 to 1.54$)$, leukaemia $(\mathrm{OR}=1.23,95 \% \mathrm{CI} 1.14$ to 1.32$)$, brain tumour $(\mathrm{OR}=1.22 ; 95 \% \mathrm{CI} 1.13$ to 1.31$)$, Ewing's sarcoma $(\mathrm{OR}=2.01,95 \%$ CI 1.45 to 2.79$)$ and neuroblastoma $(\mathrm{OR}=1.70$; $95 \%$ CI 1.14 to 2.51 ) in children. The incidence of germ-cell tumours in the exposed population did not decrease significantly $(\mathrm{OR}=0.95 ; 95 \%$ CI 0.86 to 1.03$)$, and there was a slight non-significant increase $(\mathrm{OR}=1.14 ; 95 \% \mathrm{CI} 0.98$ to 1.33$)$ in the incidence of renal tumours. 
Begg's funnel plot with pseudo $95 \%$ confidence limits

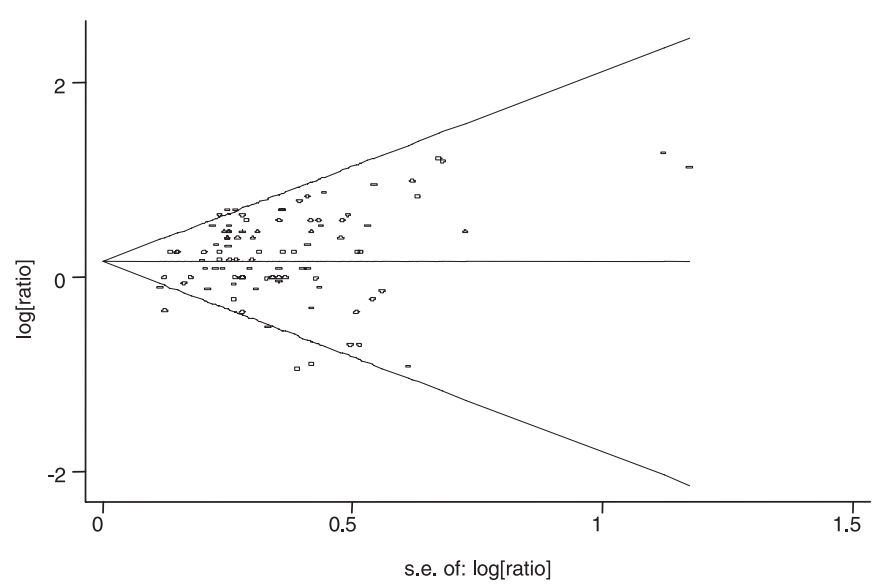

Figure 1 Begg's funnel plot with pseudo-confidence limits of $95 \%$ concerning brain cancer. To assess publication bias, we explored the effect of study size by plotting the logarithm of the estimated OR versus its SE. Publication bias is characterised by asymmetry of the funnel plot determined by the Egger test.

As the heterogeneity of each type and subtype of cancer was still significant, we defined other variables (the period of exposure, the type of exposure and the type of pesticide used) to investigate possible sources of heterogeneity.

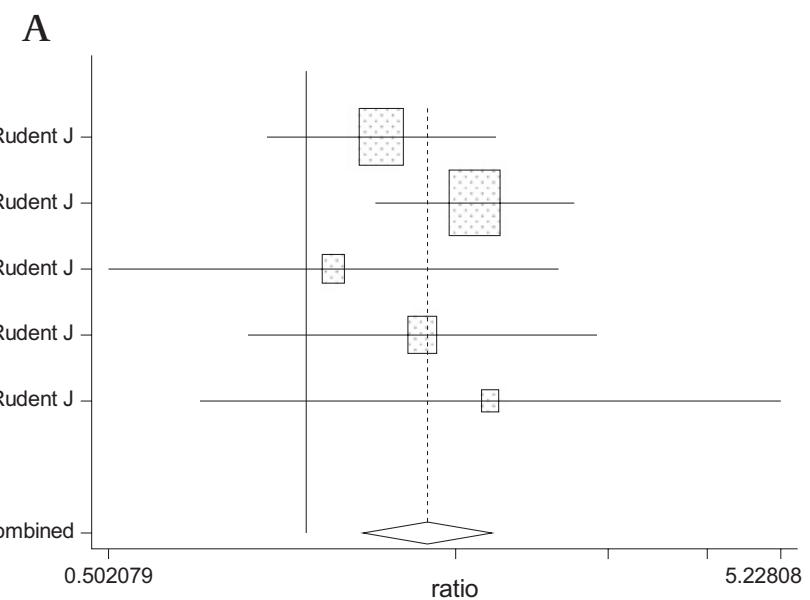

C

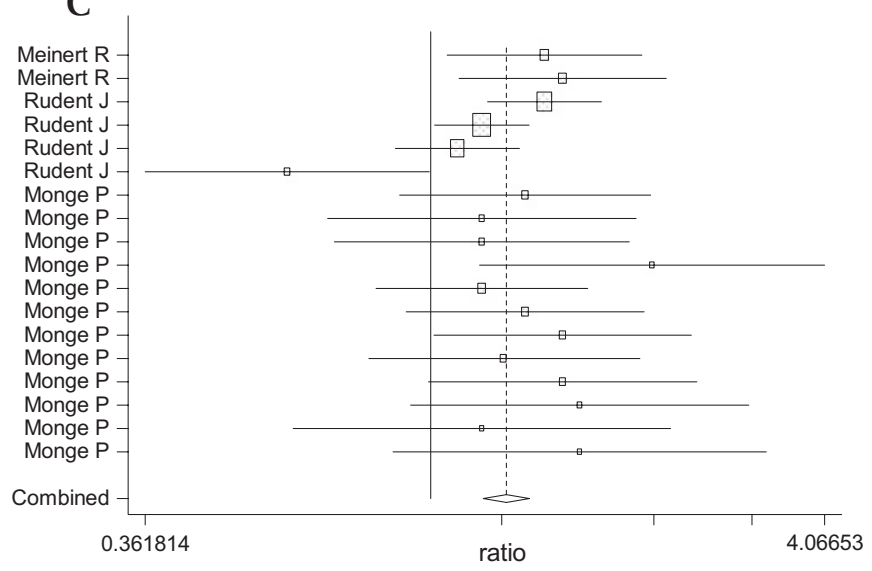

EFFECT OF THE PERIOD OF EXPOSURE ON CHILDHOOD CANCER We performed a more detailed analysis of the period of exposure of children, and in each case we calculated the meta-OR by stratifying the data as a function of the person exposed (mother, father or child). The results are presented in figure 2 and table 1. The prenatal period appears to be a critical window of exposure for the incidence of lymphoma. Although the risk of developing this type of cancer did not change significantly when children were exposed after birth, it was significantly higher when exposure occurred during the prenatal period than during the postnatal period. Moreover, the incidence of lymphoma increased by $53 \%$ when the mother was exposed during the prenatal period (figure 2A) and, to a lesser extent, when the father was exposed during the same period (figure 2D) $(\mathrm{OR}=1.37,95 \% \mathrm{CI} 1.16$ to 1.61$)$. The duration of exposure of the mother greatly increased the risk of lymphoma developing during childhood: when exposure was reported to be 'ever,' the OR value was 1.90 (95\% CI 1.14 to 3.17 ).

Leukaemia risk was associated with prenatal exposure of the mother and, to a lesser extent, of the father. The risk increased by $48 \%$ and $32 \%$ after prenatal exposure of the mother and the father respectively (figure $2 \mathrm{~B}, \mathrm{C}$ respectively). It is noteworthy that when both parents were exposed during the prenatal period, the risk of leukaemia was even higher $(84 \%$; $\mathrm{OR}=1.84$; $95 \%$ CI 1.39 to 2.44). Surprisingly, postnatal exposure of the mother had a more pronounced effect on the increased risk of leukaemia in childhood $(\mathrm{OR}=2.12 ; 95 \%$ CI 1.17 to 3.84$)$.
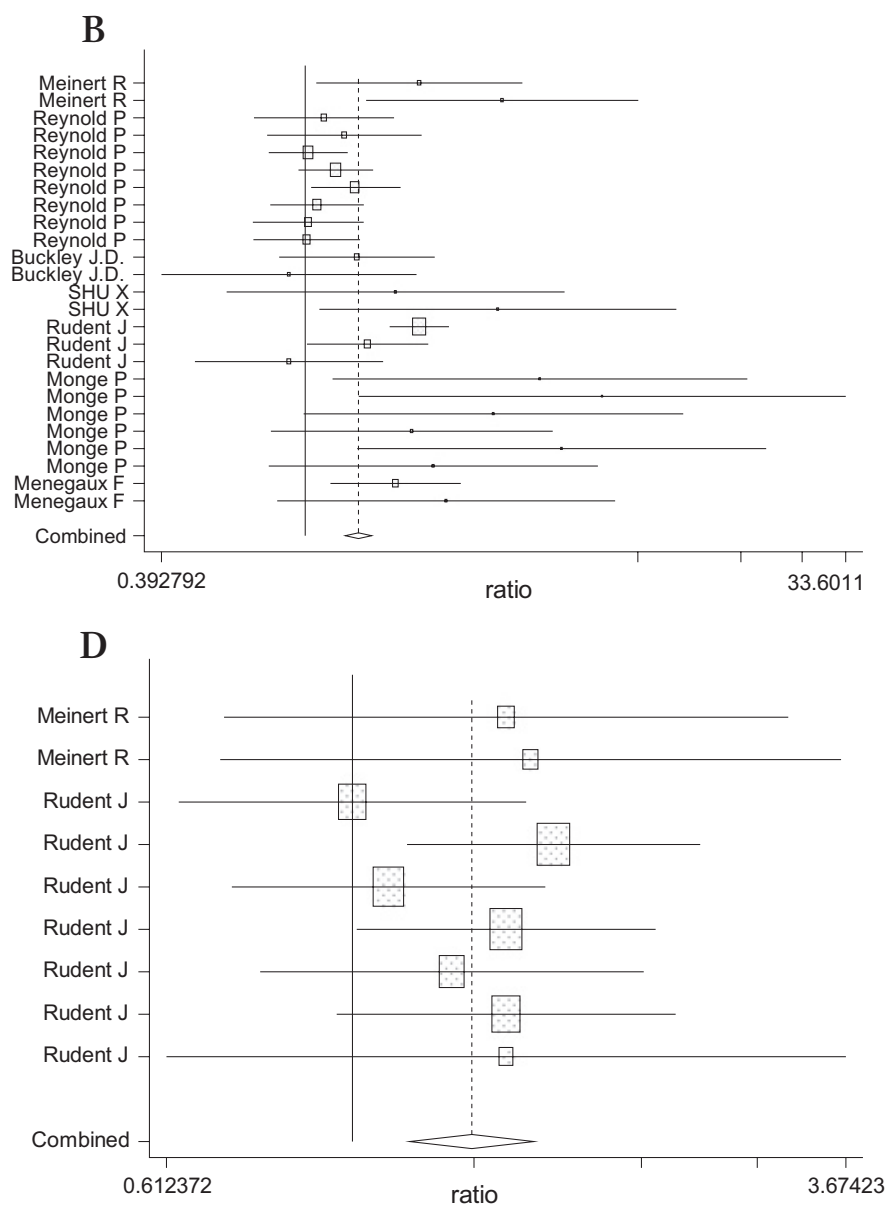

Figure 2 Forest plot of studies related to the incidence of lymphoma (A), and leukaemia (B) when mothers were exposed during the prenatal period. (C, D) Forest plots of studies related to leukaemia and lymphoma incidence respectively when the father was exposed during the prenatal period: representation of pooled OR and its $95 \% \mathrm{Cl}$ for lymphoma and leukaemia according to a fixed or random model as described in 'Materials and method' or in table 1. 
Table 1 Effect of the period of exposure on the incidence of cancers in children: number of data, model used after estimation of heterogeneity, pooled OR estimates and their $95 \% \mathrm{Cl}$ for each type of cancer

\begin{tabular}{|c|c|c|c|c|c|}
\hline & Exposed person & Lymphoma & Leukaemia & Ewing's sarcoma & Brain \\
\hline \multirow[t]{3}{*}{ Prenatal exposure } & Mother & $\begin{array}{l}5 \text { (fixed) } \\
1.53(1.22 \text { to } 1.91) \\
\text { No bias }\end{array}$ & $\begin{array}{l}25 \text { (random) } \\
1.48(1.26 \text { to } 1.75) \\
\text { No bias }\end{array}$ & ND & NS \\
\hline & Father & $\begin{array}{l}9 \text { (fixed) } \\
1.37(1.16 \text { to } 1.61)\end{array}$ & $\begin{array}{l}18 \text { (random) } \\
1.32(1.20 \text { to } 1.46)\end{array}$ & ND & $\begin{array}{l}9 \text { (fixed) } \\
1.49(1.23 \text { to } 1.79)\end{array}$ \\
\hline & Father and mother & $\begin{array}{l}\text { No bias } \\
\text { ND }\end{array}$ & $\begin{array}{l}\text { No bias } \\
4 \text { (fixed) } \\
1.84(1.39 \text { to } 2.44) \\
\text { No bias }\end{array}$ & ND & $\begin{array}{l}\text { No bias } \\
5 \text { (fixed) } \\
1.37(1.08 \text { to } 1.76 \text { ) } \\
\text { No bias }\end{array}$ \\
\hline \multirow[t]{4}{*}{ Postnatal exposure } & Mother & ND & $\begin{array}{l}3 \text { (fixed) } \\
2.12(1.17 \text { to } 3.84)\end{array}$ & ND & ND \\
\hline & Father & ND & $\begin{array}{l}4 \text { (fixed) } \\
1.33(1.07 \text { to } 1.66) \\
\text { No bias }\end{array}$ & ND & $\begin{array}{l}2 \text { (fixed) } \\
1.66(1.11 \text { to } 2.49)\end{array}$ \\
\hline & Father and mother & ND & NS & ND & ND \\
\hline & Child & NS & NS & NS & $\begin{array}{l}21 \text { (random) } \\
1.16(1.01 \text { to } 1.32)\end{array}$ \\
\hline \multirow[t]{4}{*}{ 'Ever' } & Mother & $\begin{array}{l}6 \text { (random) } \\
1.90(1.14 \text { to } 3.17) \\
\text { No bias }\end{array}$ & ND & NS & NS \\
\hline & Father & ND & NS & ND & $\begin{array}{l}10 \text { (fixed) } \\
1.41 \text { (1.11 to } 1.79 \text { ) } \\
\text { No bias }\end{array}$ \\
\hline & Father and Mother & ND & NS & ND & NS \\
\hline & Child & ND & $\begin{array}{l}2 \text { (fixed) } \\
1.85(1.15 \text { to } 2.96) \\
\text { Bias }\end{array}$ & ND & ND \\
\hline
\end{tabular}

Children were reported to be exposed 'ever' (unspecified period), after birth (postnatal exposure) or before birth (prenatal exposure) and via the father, the mother, both parents or by themselves (the child). The Cochran 0 test was used to choose the appropriate model to calculate pooled ORs. In the case of heterogeneity ( $p<0.05)$, pooled ORs were recalculated according to the random-effect model estimated using the DerSimonian \& Laird method. ${ }^{61}$ Publication bias was characterised by asymmetry of the funnel plot according to the Egger test ${ }^{64}$ (not shown). When there was bias, the pooled ORs were recalculated after applying the 'trim and fill' method. ${ }^{62}$

ND, not determined because there was no study or only one; NS, not significant.

However, this result should be interpreted with caution, since only three ORs were pooled. Table 1 also shows that the increase in incidence of brain cancers in children was more pronounced when exposure occurred during the postnatal period $(\mathrm{OR}=1.66$; $95 \%$ CI 1.11 to 2.49 ). However, it should be noted that only two studies were taken into account for the determination of the pooled OR. Here again, the prenatal period appears to be a critical window of exposure for the incidence of cancer in the offspring $(\mathrm{OR}=1.49,95 \% \mathrm{CI} 1.23$ to 1.79 when the father was exposed, and $\mathrm{OR}=1.37,95 \% \mathrm{CI} 1.08$ to 1.76 when both the father and mother were exposed). It is notable that the risk of brain cancer in children mainly increased when the father was exposed rather than the mother, whose exposure only slightly and non-significantly increased the risk. Exposure of both parents also increased the risk (37\%) but to a lesser extent.

Next we tried to stratify these data to identify the critical perinatal period (preconception, gestation, lactation) during which the mother's exposure to pesticides could have an impact on the health of her offspring. The results of our stratified analysis (not shown) did not reveal any difference between the three periods tested, probably due to the small number of data concerning this point.

\section{INFLUENCE OF THE TYPE OF EXPOSURE ON THE INCIDENCE OF CHILDHOOD CANCER}

We next checked whether the type of exposure (occupational, use of pesticides in the home or garden, the proximity of the home to an agricultural area) could play a role in the risk of developing these diseases. The results of this analysis are presented in table 2. No significant risk of developing lymphoma or leukaemia or a brain tumour was found in children whose parents lived in an active agricultural area. The risk of brain cancer was significantly associated with both occupational and residential exposure of fathers (figure $3 \mathrm{~A}, \mathrm{~B}$ respectively) $(\mathrm{OR}=1.40 ; 95 \%$ CI 1.20 to 1.62 and $\mathrm{OR}=1.48 ; 95 \%$ CI 1.22 to 1.80 respectively). The risk of developing Ewing's sarcoma increased when fathers were occupationally exposed to pesticides ( $O R=2.34 ; 95 \%$ CI 1.33 to 4.12 ) although it should be borne in mind that only three ORs were pooled. On the other hand, the risk of lymphoma and leukaemia increased by 48 and $56 \%$ respectively when the mother used pesticides in the home or garden.

\section{INFLUENCE OF THE CLASS OF PESTICIDES ON THE INCIDENCE OF CHILDHOOD CANCER}

The last step of our meta-analysis focused on the influence of the type of pesticide on the incidence of childhood cancer. Results are presented in table 3. The risk of lymphoma was correlated with exposure to both insecticides and fungicides $(\mathrm{OR}=1.46 ; 95 \% \mathrm{CI} 1.20$ to 1.78 and $\mathrm{OR}=1.45 ; 95 \% \mathrm{CI} 1.06$ to 1.99 respectively) and, to a lesser extent, to herbicides $(\mathrm{OR}=1.31$; $95 \%$ CI 1.02 to 1.67$)$. The risk of leukaemia was associated with exposure to herbicides and, to a lesser extent, with exposure to insecticides ( $\mathrm{OR}=1.26 ; 95 \%$ CI 1.14 to 1.39 and $\mathrm{OR}=1.17 ; 95 \% \mathrm{CI} 1.03$ to 1.33 respectively). The risk of brain cancer was also correlated with exposure to herbicides and fungicides $(\mathrm{OR}=1.31 ; 95 \% \mathrm{CI} 1.08$ to 1.60 and $\mathrm{OR}=1.32 ; 95 \% \mathrm{CI}$ 1.06 to 1.65 respectively) and, to a lesser extent, with exposure to insecticides $(\mathrm{OR}=1.18 ; 95 \%$ CI 1.06 to 1.33$)$.

\section{DISCUSSION}

The aetiology of childhood cancers remains largely unknown, and it has been hypothesised that environmental factors could play a role. ${ }^{67}$ Previous excellent reviews revealed positive and 
Table 2 Effect of the type of exposure (professional or not professional) on the incidence of childhood cancer: pooled OR estimates and their $95 \% \mathrm{Cl}$ for each type of cancer

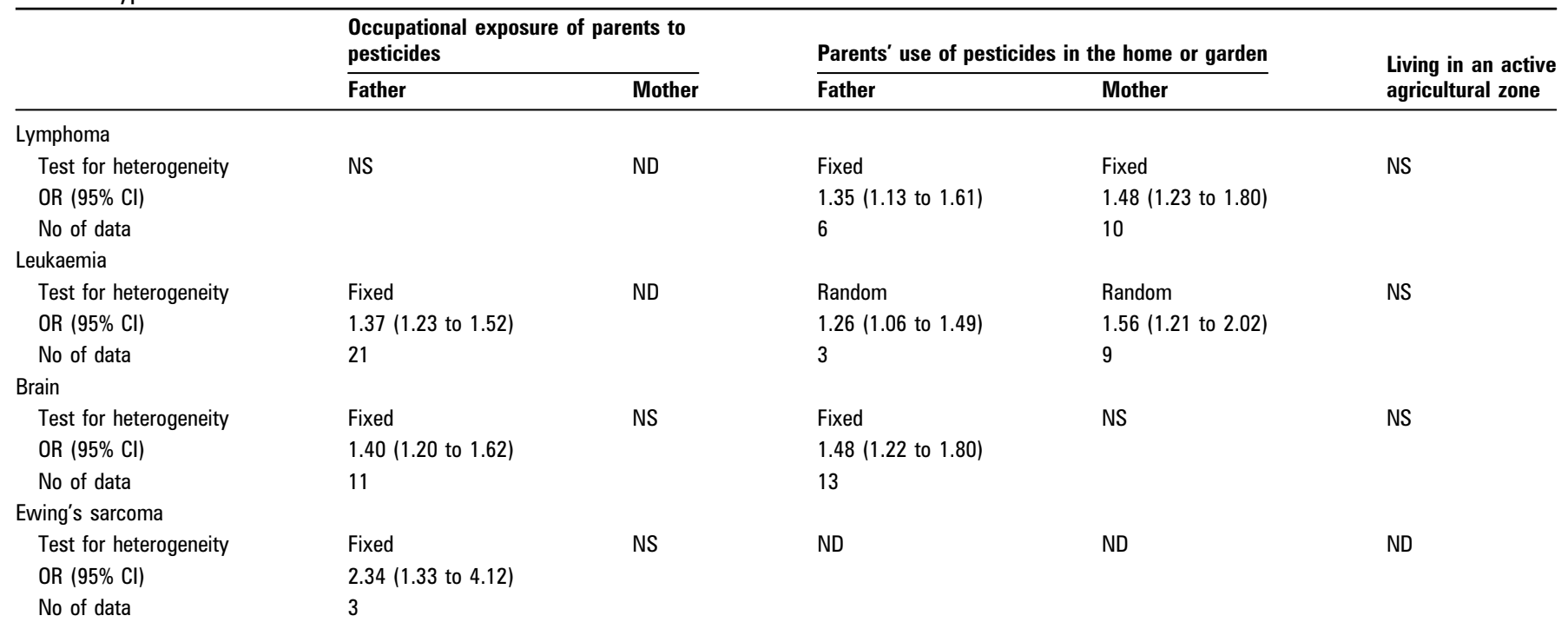

Children were exposed via the professional use of pesticides by their father or mother, or via the use by the mother or father of pesticides in the home or garden or because they lived in an active agricultural area. The Cochran 0 test was used to choose the appropriate model to calculate pooled ORs. In the case of heterogeneity ( $<<0.05)$, pooled 0 Rs were recalculated according to the random-effect model estimated using the DerSimonian and Laird method. No bias was determined using the Egger test.

ND, not determined because there was no study or only one; NS, not significant.

negative associations between parental exposure to pesticides and the incidence of the main childhood cancers. ${ }^{15} 6869 \mathrm{We}$ performed a meta-analysis on 40 papers (including case-control and cohort studies) in order to update these data.

From our study, it appears that exposure to pesticides is significantly associated with an increased risk of leukaemia, lymphoma and brain cancer in children. A strong association was found between the incidence of neuroblastoma and Ewing's sarcoma and exposure to pesticides. However, our results should be interpreted with caution because of the small number of reports analysed. These cancers are rare, and a meta-analysis was performed on only four and nine datasets respectively. No correlation was found between parental exposure to pesticides and renal cancer or germ-cell tumours in children. Conversely, our results showed that the risk of leukaemia and lymphoma in children was high when their mothers were exposed during the prenatal period and when they used pesticides in the home or garden ( $\mathrm{OR}=1.48$ (1.26-1.75 and 1.53 (1.22-1.99) respectively).
Interestingly, the incidence of childhood brain cancer was high $(\mathrm{OR}=1.49$ (1.23-1.79)) when the father was exposed during the prenatal period. In addition, occupational exposure of the father as well as use of pesticides in the home or in the garden was also found to influence the risk of brain cancer in the offspring $(\mathrm{OR}=1.40$ (1.20-1.62) and $\mathrm{OR}=1.48$ (1.22-1.80) respectively). The proximity of the home to a farm or an active agricultural area was not associated with an increased risk of the cancers we studied.

Our results point to the prenatal period as a high-risk window of exposure to pesticides and show that exposure of both the father and mother to pesticides may be linked to the incidence of different cancer sites in childhood. This result indeed suggests that the type of pesticides used and the degree or frequency of exposure may differ depending on the gender of the parent. Moreover, exposure to household and garden pesticides appears to be a high-risk factor for the development of leukaemia, lymphoma and brain cancer in children, whereas occupational
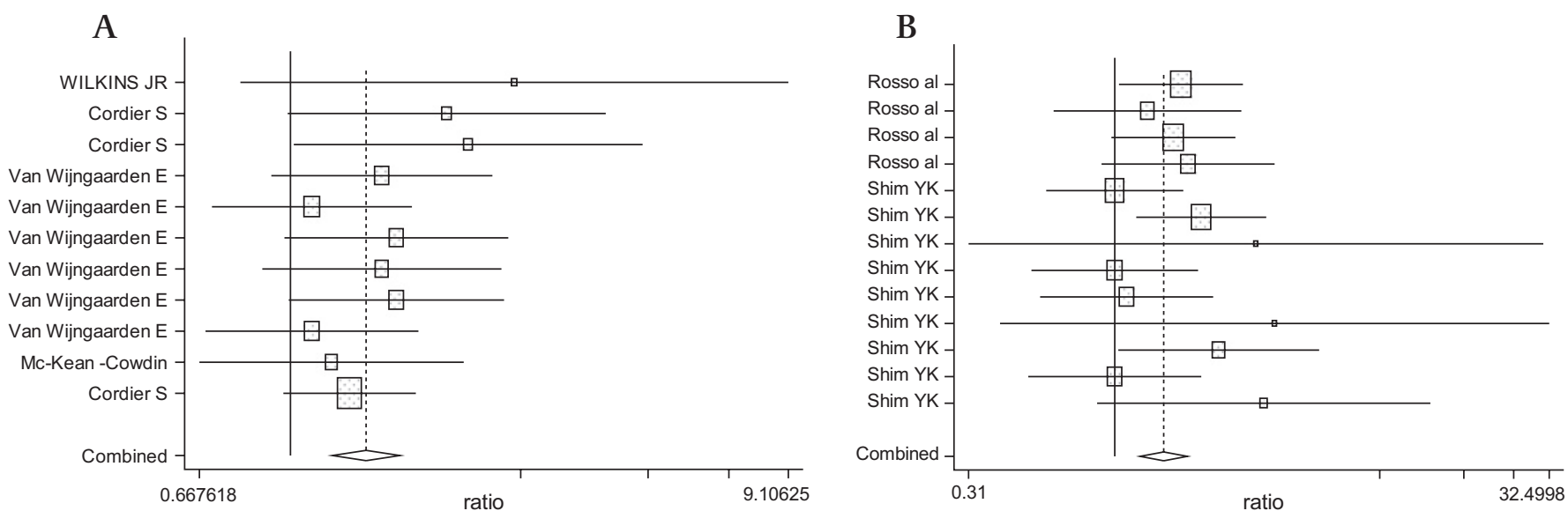

Figure 3 Forest plot of studies related to the incidence of brain cancer when the father was exposed professionally or at home (A, B respectively): representation of pooled $\mathrm{OR}$ and its $95 \% \mathrm{Cl}$ for brain cancer according to a fixed or random model as described in 'Materials and methods' or in table 2 . 
Table 3 Influence of the class of pesticide on the incidence of childhood cancer: pooled OR estimates and their $95 \% \mathrm{Cl}$ for the incidence of leukaemia, lymphoma and brain cancer as a function of the class of pesticide (herbicide, insecticide and fungicide)

\begin{tabular}{llll}
\hline Type of cancer & Herbicide & Insecticide & Fungicide \\
\hline $\begin{array}{l}\text { Lymphoma } \\
\text { Test for heterogeneity }\end{array}$ & Fixed & Random & Fixed \\
$\begin{array}{l}\text { OR }(95 \% \text { Cl) } \\
\text { No of data }\end{array}$ & $1.31(1.02$ to 1.67$)$ & $1.46(1.20$ to 1.78$)$ & 1.45 (1.06 to 1.99) \\
$\begin{array}{l}\text { Leukaemia } \\
\text { Test for heterogeneity }\end{array}$ & 4 & 11 & 3 \\
OR (95\% Cl) & Fixed & Random & NS \\
No of data & $1.26(1.14$ to 1.39$)$ & $1.17(1.03$ to 1.33$)$ & \\
Brain & 20 & 45 & \\
Test for heterogeneity & Random & & Fixed \\
OR (95\% Cl) & $1.31(1.08$ to 1.60$)$ & $1.18(1.06$ to 1.33$)$ & 1.32 (1.06 to 1.65$)$ \\
No of data & 16 & 24 & 15 \\
\hline
\end{tabular}

The Cochran 0 test was used to choose the appropriate model to calculate pooled ORs. In the case of heterogeneity $(p<0.05)$, pooled ORs were recalculated according to the random-effect model estimated using the DerSimonian and Laird method. No bias was determined using the Egger test.

NS, not significant.

exposure to pesticides is mainly positively correlated with brain cancer and Ewing's sarcoma. In the case of professional exposure, the type of pesticides used in agriculture and the degree or frequency of exposure undoubtedly differ from residential exposure. ${ }^{45}$ Investigators in the Northern California Childhood Leukemia study included a comprehensive assessment of residential exposure to pesticides ${ }^{70}$ and provided more precise details concerning the relationship between residential exposure to pesticides and childhood leukaemia. Stratification by biocide category showed statistically significant increased risks of childhood lymphoma and of childhood leukaemia for the group of studies on exposure to insecticides and herbicide respectively. Data on the impact of exposure to herbicides or fungicides and to the three classes of pesticides on the respective incidence of lymphoma and brain cancer were less consistent.

When assessing environmental health impacts, children, fetuses and neonates need to be distinguished from adults, as they are believed to be more vulnerable to the effects of environmental pollutants, ${ }^{68}$ and many routes of exposure are possible. Depending on the developmental period, children could be exposed via the placenta, maternal milk, the skin and the digestive tract (WHO 2006 (principles for evaluating health risks in children associated with exposure to chemicals in Environmental Health Criteria (Unedited draft) IPCS, ed., p. 302, WHO, Geneva). ${ }^{71}$ The lungs and/or air are also a potentially important source of exposure to pesticides used at home or when the home is located near farms or orchards. Paternal germ cells could also be the target of pesticides via a direct effect resulting in heritable genetic damage or in epigenetic changes that alter gene function. ${ }^{872}$ This could explain the strong correlation between paternal exposure and the increased incidence of brain cancer. However, several other possible mechanisms could explain this association, especially indirect mechanisms such as household contamination with substances brought home on the father's clothing. ${ }^{8}$

Exposure to pesticides during fetal development is due to the capacity of these compounds to pass through the placental barrier and into the fetal bloodstream. ${ }^{73}$ 74 The association between the concentration of pesticides in the biological fluid and childhood health problems is well documented. ${ }^{12} 75-77$ It is well established that the beginning of the initial event leading to some infant or young children cancers occurs in utero. ${ }^{12} 78$ Together with the positive association revealed in our metaanalyses between parental exposure and some childhood cancers, these data lead us to suggest that pesticides present in parent tissue or fluid could be responsible for the genetic modifications in the fetus or in parental germinal cells that lead to cancer.

While our results do provide evidence of an association between pesticide exposure and the risk of some childhood cancers, some limitations of our meta-analysis have to be addressed, and many questions still remain to be answered (the vulnerable window and the frequency of exposure during the prenatal period, for example). Moreover, the use of multiple point estimates from the same publication, although independent, may lead to potential bias or heterogeneity. However, these parameters were evaluated and taken into account in the assessment of the pooled ORs throughout our analysis. One other limitation in our study could be that the assessment of potential risk factors for childhood cancers was performed from a majority of case-control studies and only two cohorts. The general limitations of case-control studies include the response bias due to the use of retrospectively collected data to assess exposure. The use of cohort approaches offers the possibility of collecting individual information on exposure to biomarkers or prospective measurement of the environmental effects of pesticides. ${ }^{79}$ However, the incidence of a disease in a cohort is often evaluated as an RR, which is not statistically compatible with the methods used in our meta-analysis which had been validated in a previous work. ${ }^{62}$ Indeed, we performed a separate metaanalysis of three cohort studies with RR values: (1) Kristensen et $a l,{ }^{58}$ who showed an association between brain cancer and factors linked to horticulture and use of pesticides; (2) Feychting et $a l,{ }^{57}$ who demonstrated that paternal occupational exposure to pesticides was associated with an increased risk of tumours of the nervous system; and (3) Reynolds et al, ${ }^{59}$ who observed little evidence of any association between the incidence of childhood cancers and residence in an agricultural area characterised by intensive use of pesticides. The result of this meta-analysis did not show any positive correlation between parental exposure to pesticide and childhood cancer incidence. This result must be considered carefully because of the small number of data and because exposures of parents were different in these studies. On the other hand, three very recent reviews and meta-analyses $^{80-83}$ showed a significantly elevated risk of childhood leukaemia associated with paternal and maternal occupational and/or residential exposure. These studies complete and reinforce these data on the incidence of leukaemia. 
In conclusion, despite some limitations in our study, our results do provide evidence concerning the sites of childhood cancer most associated with pesticide exposure, the period and type of exposure as well as the type of pesticide that could increase the risk of developing childhood cancer. The causality of these associations is not proven, and the hypothesis of an environmental origin of some cancers requires experimental studies. Taken together with the results of our previous study, ${ }^{62}$ the results of the present work convinced us of the need to conduct experimental studies to confirm and explain these correlations.

\section{Competing interests None.}

Provenence and peer review Not commissioned; externally peer reviewed.

\section{REFERENCES}

1. Desandes $\mathbf{E}$, Lacour B, Sommelet D, et al. Cancer incidence among adolescents in France. Pediatr Blood Cancer 2004;43:742-8.

2. Desandes $\mathbf{E}$, Clavel J, Berger $\mathrm{C}$, et al. Cancer incidence among children in France, 1990-1999. Pediatr Blood Cancer 2004;43:749-57.

3. Clavel J. Epidemiologie des cancers de l'enfant. La revue du Praticien 2007;57:1061-9. [in French].

4. Stiller CA, Desandes E, Danon SE, et al. Cancer incidence and survival in European adolescents (1978-1997). Report from the Automated Childhood Cancer Information System project. Eur J Cancer 2006;42:2006-18.

5. Desandes $\mathbf{E}$, Lacour $B$, Sommelet $D$, et al. Cancer survival among adolescents in France. Eur J Cancer 2006;42:403-9.

6. Buka I, Koranteng S, Osornio Vargas AR. Trends in childhood cancer incidence: review of environmental linkages. Pediatr Clin North Am 2007:54:177-203.

7. Shannon K. Genetic predispositions and childhood cancer. Environ Health Perspect 1998;106(Suppl 3):801-6.

8. Olshan AF, van Wijngaarden E. Paternal occupation and childhood cancer. Adv Exp Med Biol 2003;518:147-61.

9. Weselak M, Arbuckle TE, Foster W. Pesticide exposures and developmental outcomes: the epidemiological evidence. J Toxicol Environ Health B Crit Rev 2007; 10:41-80.

10. Weselak M, Arbuckle TE, Wigle DT, et al. In utero pesticide exposure and childhood morbidity. Environ Res 2007:103:79-86.

11. Infante-Rivard C, Weichenthal S. Pesticides and childhood cancer: an update of Zahm and Ward's 1998 review. J Toxicol Environ Health B Crit Rev 2007:10:81-99.

12. Lafiura KM, Bielawski DM, Posecion NC Jr, et al. Association between prenatal pesticide exposures and the generation of leukemia-associated T(8;21). Pediatr Blood Cancer 2007:49:624-8.

13. Agopian J, Navarro JM, Gac AC, et al. Agricultural pesticide exposure and the molecular connection to lymphomagenesis. J Exp Med 2009;206:1473-83.

14. Daniels JL, Olshan AF, Savitz DA. Pesticides and childhood cancers. Environ Health Perspect 1997:105:1068-77.

15. Nasterlack M. Pesticides and childhood cancer: an update. Int J Hyg Environ Health 2007;210:645-57.

16. Wilkins JR 3rd, Sinks T. Parental occupation and intracranial neoplasms of childhood: results of a case-control interview study. Am J Epidemiol 1990;132:275-92.

17. Chen Z, Stewart PA, Davies S, et al. Parental occupational exposure to pesticides and childhood germ-cell tumors. Am J Epidemiol 2005;162:858-67.

18. Meinert R, Schuz J, Kaletsch U, et al. Leukemia and non-Hodgkin's lymphoma in childhood and exposure to pesticides: results of a register-based case-control study in Germany. Am J Epidemiol 2000;151:639-46; discussion 47-50.

19. Holly EA, Bracci PM, Mueller BA, et al. Farm and animal exposures and pediatric brain tumors: results from the United States West Coast Childhood Brain Tumor Study. Cancer Epidemiol Biomarkers Prev 1998;7:797-802

20. Schuz J, Kaletsch U, Kaatsch P, et al. Risk factors for pediatric tumors of the central nervous system: results from a German population-based case-control study. Med Pediatr Oncol 2001;36:274-82.

21. Kaatsch P, Kaletsch U, Meinert R, et al. German case control study on childhood leukaemia-basic considerations, methodology and summary of the results. Klin Padiatr 1998:210:185-91.

22. Ma X, Buffler PA, Selvin S, et al. Daycare attendance and risk of childhood acute lymphoblastic leukaemia. Br J Cancer 2002;86:1419-24.

23. Reynolds P, Von Behren J, Gunier RB, et al. Agricultural pesticide use and childhood cancer in California. Epidemiology 2005;16:93-100.

24. Reynolds P, Von Behren J, Gunier R, et al. Agricultural pesticides and lymphoproliferative childhood cancer in California. Scand J Work Environ Health 2005;31(Suppl 1):46-54; discussion 5-7.

25. Cordier S, Lefeuvre B, Filippini G, et al. Parental occupation, occupational exposure to solvents and polycyclic aromatic hydrocarbons and risk of childhood brain tumors (Italy, France, Spain). Cancer Causes Control 1997;8:688-97.

26. Valery PC, McWhirter W, Sleigh A, et al. Farm exposures, parental occupation, and risk of Ewing's sarcoma in Australia: a national case-control study. Cancer Causes Control 2002;13:263-70.
27. Buckley JD, Meadows AT, Kadin ME, et al. Pesticide exposures in children with non-Hodgkin lymphoma. Cancer 2000;89:2315-21.

28. Cordier S, Iglesias MJ, Le Goaster $C$, et al. Incidence and risk factors for childhood brain tumors in the lle de France. Int J Cancer 1994:59:776-82.

29. Buckley JD, Robison LL, Swotinsky R, et al. Occupational exposures of parents of children with acute nonlymphocytic leukemia: a report from the Childrens Cancer Study Group. Cancer Res 1989;49:4030-7.

30. Shu X0, Gao YT, Brinton LA, et al. A population-based case-control study of childhood leukemia in Shanghai. Cancer 1988:62:635-44.

31. Davis JR, Brownson RC, Garcia R, et al. Family pesticide use and childhood brain cancer. Arch Environ Contam Toxicol 1993;24:87-92.

32. Cooney MA, Daniels JL, Ross JA, et al. Household pesticides and the risk of Wilms tumor. Environ Health Perspect 2007;115:134-7.

33. Chen Z, Robison L, Giller R, et al. Environmental exposure to residential pesticides, chemicals, dusts, fumes, and metals, and risk of childhood germ cell tumors. Int J Hyg Environ Health 2006;209:31-40.

34. Rudant J, Menegaux F, Leverger G, et al. Household exposure to pesticides and risk of childhood hematopoietic malignancies: the ESCALE study (SFCE). Environ Health Perspect 2007;115:1787-93.

35. Monge P, Wesseling C, Guardado J, et al. Parental occupational exposure to pesticides and the risk of childhood leukemia in Costa Rica. Scand J Work Environ Health 2007;33:293-303.

36. van Wijngaarden $\mathbf{E}$, Stewart PA, Olshan AF, et al. Parental occupational exposure to pesticides and childhood brain cancer. Am J Epidemiol 2003;157:989-97.

37. Menegaux F, Baruchel A, Bertrand $Y$, et al. Household exposure to pesticides and risk of childhood acute leukaemia. Occup Environ Med 2006;63:131-4.

38. Efird JT, Holly EA, Preston-Martin S, et al. Farm-related exposures and childhood brain tumours in seven countries: results from the SEARCH International Brain Tumour Study. Paediatr Perinat Epidemiol 2003;17:201-11.

39. Walker KM, Carozza S, Cooper S, et al. Childhood cancer in Texas counties with moderate to intense agricultural activity. J Agric Saf Health 2007; 13:9-24

40. Abadi-Korek I, Stark B, Zaizov R, et al. Parental occupational exposure and the risk of acute lymphoblastic leukemia in offspring in Israel. J Occup Environ Med 2006;48:165-74

41. McKean-Cowdin R, Preston-Martin S, Pogoda JM, et al. Parental occupation and childhood brain tumors: astroglial and primitive neuroectodermal tumors. J Occup Environ Med 1998;40:332-40.

42. Olshan AF, De Roos AJ, Teschke K, et al. Neuroblastoma and parental occupation Cancer Causes Control 1999;10:539-49.

43. Cordier S, Mandereau L, Preston-Martin S, et al. Parental occupations and childhood brain tumors: results of an international case-control study. Cancer Causes Control 2001;12:865-74.

44. Moore LE, Gold L, Stewart PA, et al. Parental occupational exposures and Ewing's sarcoma. Int J Cancer 2005;114:472-8.

45. Daniels JL, Olshan AF, Teschke K, et al. Residential pesticide exposure and neuroblastoma. Epidemiology 2001;12:20-7.

46. Kerr MA, Nasca PC, Mundt KA, et al. Parental occupational exposures and risk of neuroblastoma: a case-control study (United States). Cancer Causes Control 2000:11:635-43.

47. Heacock H, Hertzman C, Demers PA, et al. Childhood cancer in the offspring of male sawmill workers occupationally exposed to chlorophenate fungicides. Environ Health Perspect 2000;108:499-503.

48. Flower KB, Hoppin JA, Lynch CF, et al. Cancer risk and parental pesticide application in children of Agricultural Health Study participants. Environ Health Perspect 2004;112:631-5.

49. Pogoda JM, Preston-Martin S. Household pesticides and risk of pediatric brain tumors. Environ Health Perspect 1997:105:1214-20.

50. Rosso AL, Hovinga ME, Rorke-Adams LB, et al. A case-control study of childhood brain tumors and fathers' hobbies: a Children's Oncology Group study. Cancer Causes Control 2008:19:1201-7.

51. Spix C, Schulze-Rath R, Kaatsch P, et al. Case-control study on risk factors for leukaemia and brain tumours in children under 5 years in Germany. Klin Padiatr 2009:221:362-8.

52. Rull RP, Gunier R, Von Behren J, et al. Residential proximity to agricultural pesticide applications and childhood acute lymphoblastic leukemia. Environ Res 2009; 109:891-9.

53. Ward MH, Colt JS, Metayer C, et al. Residential exposure to polychlorinated biphenyls and organochlorine pesticides and risk of childhood leukemia. Environ Health Perspect 2009;117:1007-13.

54. Shim YK, Mlynarek SP, van Wijngaarden E. Parental exposure to pesticides and childhood brain cancer: U.S. Atlantic coast childhood brain cancer study. Environ Health Perspect 2009;117:1002-6.

55. Carozza SE, Li B, Wang Q, et al. Agricultural pesticides and risk of childhood cancers. Int J Hyg Environ Health 2009:212:186-95.

56. Pearce MS, Parker L. Paternal employment in agriculture and childhood kidney cancer. Pediatr Hematol Oncol 2000;17:223-30.

57. Feychting $\mathbf{M}$, Plato N, Nise G, et al. Paternal occupational exposures and childhood cancer. Environ Health Perspect 2001;109:193-6.

58. Kristensen P, Andersen A, Irgens LM, et al. Cancer in offspring of parents engaged in agricultural activities in Norway: incidence and risk factors in the farm environment. Int J Cancer 1996;65:39-50. 
59. Reynolds P, Von Behren J, Gunier RB, et al. Childhood cancer and agricultural pesticide use: an ecologic study in California. Environ Health Perspect 2002;110:319-24.

60. Mantel N, Haenszel W. Statistical aspects of the analysis of data from retrospective studies of disease. J Natl Cancer Inst 1959;22:719-48.

61. DerSimonian R, Laird N. Meta-analysis in clinical trials. Control Clin Trials 1986;7:177-88

62. Merhi M, Raynal H, Cahuzac E, et al. Occupational exposure to pesticides and risk of hematopoietic cancers: meta-analysis of case-control studies. Cancer Causes Control 2007;18:1209-26.

63. Poole C, Greenland S. Random-effects meta-analyses are not always conservative. Am J Epidemiol 1999:150:469-75.

64. Egger M, Davey Smith G, Schneider M, et al. Bias in meta-analysis detected by a simple, graphical test. BMJ 1997;315:629-34.

65. Duval S, Tweedie R. Trim and fill: a simple funnel-plot-based method of testing and adjusting for publication bias in meta-analysis. Biometrics 2000;56:455-63.

66. Ma X, Buffler PA, Gunier RB, et al. Critical windows of exposure to household pesticides and risk of childhood leukemia. Environ Health Perspect 2002;110:955-60.

67. Alavanja MC, Ward MH, Reynolds P. Carcinogenicity of agricultural pesticides in adults and children. J Agromedicine 2007;12:39-56.

68. Zahm SH, Ward MH. Pesticides and childhood cancer. Environ Health Perspect 1998;106(Suppl 3):893-908.

69. Khuder SA, Schaub EA, Keller-Byrne JE. Meta-analyses of non-Hodgkin's lymphoma and farming. Scand J Work Environ Health 1998;24:255-61.

70. Metayer C, Buffler PA. Residential exposures to pesticides and childhood leukaemia. Radiat Prot Dosimetry 2008;132:212-19.

71. Perera F, Viswanathan S, Whyatt R, et al. Children's environmental health research-highlights from the Columbia Center for Children's Environmental Health. Ann N Y Acad Sci 2006;1076:15-28.

72. Cordier S. Evidence for a role of paternal exposures in developmental toxicity. Basic Clin Pharmacol Toxicol 2008;102:176-81.
73. Nagayama J, Kohno $\mathrm{H}$, Kunisue $\mathrm{T}$, et al. Concentrations of organochlorine pollutants in mothers who gave birth to neonates with congenital hypothyroidism. Chemosphere 2007:68:972-6.

74. Nagayama J, Tsuji H, lida T, et al. Immunologic effects of perinatal exposure to dioxins, PCBs and organochlorine pesticides in Japanese infants. Chemosphere 2007:67:S393-8.

75. Behrooz RD, Sari AE, Bahramifar N, et al. Organochlorine pesticide and polychlorinated biphenyl residues in human milk from the Southern Coast of Caspian Sea, Iran. Chemosphere 2009;74:931-7.

76. Glynn A, Thuvander A, Aune $\mathrm{M}$, et al. Immune cell counts and risks of respiratory infections among infants exposed pre- and postnatally to organochlorine compounds: a prospective study. Environ Health 2008;7:62

77. Samarawickrema N, Pathmeswaran A, Wickremasinghe R, et al. Fetal effects of environmental exposure of pregnant women to organophosphorus compounds in a rural farming community in Sri Lanka. Clin Toxicol (Phila) 2008;46:489-95.

78. Wiemels JL, Cazzaniga G, Daniotti $\mathrm{M}$, et al. Prenatal origin of acute lymphoblastic leukaemia in children. Lancet 1999;354:1499-503.

79. Ritz B, Rull RP. Assessment of environmental exposures from agricultural pesticides in childhood leukaemia studies: challenges and opportunities. Radiat Prot Dosimetry 2008:132:148-55.

80. Van Maele-Fabry G, Lantin AC, Hoet P, et al. Childhood leukaemia and parental occupational exposure to pesticides: a systematic review and meta-analysis. Cancer Causes Control 2010:21:787-809.

81. Turner MC, Wigle DT, Krewski D. Residential pesticides and childhood leukemia: a systematic review and meta-analysis. Environ Health Perspect 2010;118:33-41.

82. Van Maele-Fabry G, Lantin AC, Hoet $P$, et al. Residential exposure to pesticides and childhood leukaemia: a systematic review and meta-analysis. Environ Int 2011:37:280-91.

83. Wigle DT, Turner MC, Krewski D. A systematic review and meta-analysis of childhood leukemia and parental occupational pesticide exposure. Environ Health Perspect 2009;117:1505-13.

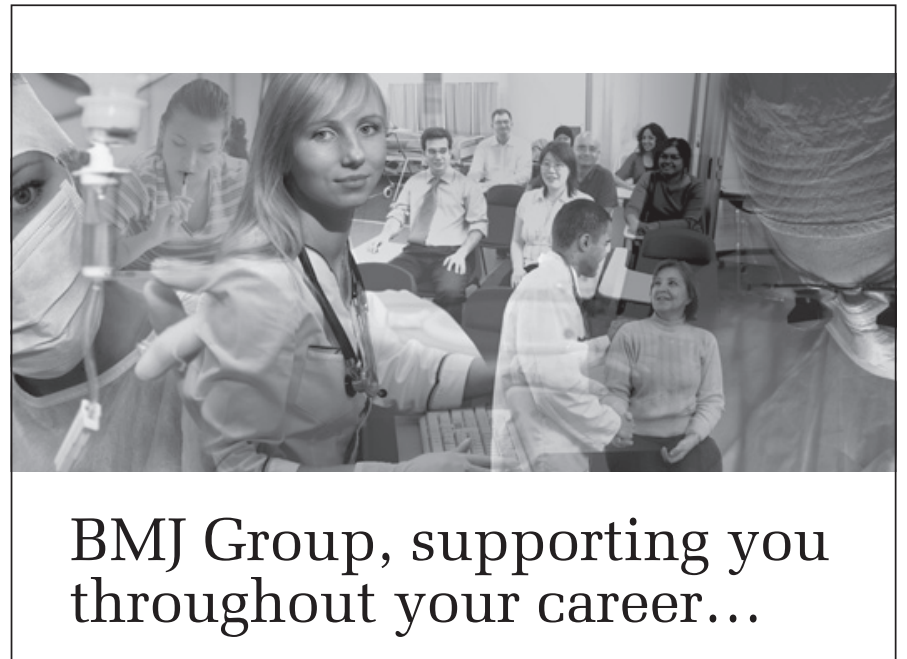

BMJ BMJ BMJIJournals BMJICareers BMJIEvidence Centre BMJILearning (BMyjumed 


\section{Exposure to pesticides and risk of childhood cancer: a meta-analysis of recent epidemiological studies}

Florence Vinson, Maysaloun Merhi, Isabelle Baldi, et al.

Occup Environ Med 2011 68: 694-702 originally published online May 23, 2011

doi: 10.1136/oemed-2011-100082

Updated information and services can be found at:

http://oem.bmj.com/content/68/9/694.full.html

\section{These include:}

Data Supplement

References

Email alerting service
"Web Only Data"

http://oem.bmj.com/content/suppl/2011/09/26/68.9.694.DC1.html

This article cites 83 articles, 12 of which can be accessed free at: http://oem.bmj.com/content/68/9/694.full.html\#ref-list-1

Receive free email alerts when new articles cite this article. Sign up in the box at the top right corner of the online article.

Notes

To request permissions go to:

http://group.bmj.com/group/rights-licensing/permissions

To order reprints go to:

http://journals.bmj.com/cgi/reprintform

To subscribe to BMJ go to:

http://group.bmj.com/subscribe/ 